\title{
Altered expression profile of glycolytic enzymes during testicular ischemia reperfusion injury is associated with the p53/TIGAR pathway: Effect of fructose 1,6-bisphosphate
}

\author{
May Al-Maghrebi ${ }^{\text {Corresp., }}{ }^{1}$, Waleed M Renno ${ }^{2}$ \\ 1 Faculty of Medicine - Department of Biochemistry, Kuwait University, Safat, Kuwait \\ 2 Faculty of Medicine - Department of Anatomy, Kuwait University, Safat, Kuwait, Kuwait \\ Corresponding Author: May Al-Maghrebi \\ Email address: malmaghrebi@hsc.edu.kw
}

Background: Testicular ischemia reperfusion injury (tIRI) is considered the mechanism underlying the pathology of testicular torsion and detorsion. Left untreated, tIRI can induce testis dysfunction, damage to spermatogenesis and possible infertility. In this study, we aimed to assess the activities and expression of glycolytic enzymes (GEs) in the testis and their possible modulation during tIRI. The effect of fructose 1,6-bisphosphate (FBP), a glycolytic intermediate, on tIRI was also investigated.

Methods: Male Sprague-Dawley rats were divided into three groups: sham, unilateral tIRI, and tIRI + FBP $(2 \mathrm{mg} / \mathrm{kg}$ ). tIRI was induced by occlusion of the testicular artery for $1 \mathrm{~h}$ followed by $4 \mathrm{~h}$ of reperfusion. FBP was injected peritoneally 30 min prior to reperfusion. Histological and biochemical analyses were used to assess damage to spermatogenesis, activities of major GEs, and energy and oxidative stress markers. The relative mRNA expression of GEs was evaluated by real-time PCR. ELISA and immunohistochemistry were used to evaluate the expression of p53 and TP53-induced glycolysis and apoptosis regulator (TIGAR).

Results: Histological analysis revealed tIRI-induced spermatogenic damage as represented by a significant decrease in the Johnsen biopsy score. In addition, tIRI reduced the activities of hexokinase 1 , phosphofructokinase-1, glyceraldehyde 3-phosphate dehydrogenase, and lactate dehydrogenase C. However, mRNA expression downregulation was detected only for hexokinase 1, phosphoglycerate kinase 2, and lactate dehydrogenase C. ATP and NADPH depletion was also induced by tIRI and was accompanied by an increased Malondialdehyde concentration, reduced glutathione level, and reduced superoxide dismutase and catalase enzyme activities. FickThe immunoexpression of p53 and TIGAR was markedly increased after tIRI. The above tIRI-induced alterations were attenuated by FBP treatment.

Discussion: Our findings indicate that tIRI-induced spermatogenic damage is associated with dysregulation of GE activity and gene expression, which were associated with activation of the TIGAR/p53 pathway. FBP treatment had a beneficial effect on alleviating the damaging effects of tIRI. This study further emphasizes the importance of metabolic regulation for proper spermatogenesis. 
1 The altered expression profile of glycolytic enzymes during testicular ischemia reperfusion

2 injury is associated with the p53/TIGAR pathway: Effect of fructose 1,6-bisphosphate

3

4
May Al-Maghrebi ${ }^{1 *}$, Waleed M. Renno ${ }^{2}$

Departments of ${ }^{1}$ Biochemistry and ${ }^{2}$ Anatomy, Faculty of Medicine-Kuwait University, Jabriyah, Kuwait

${ }^{*}$ Corresponding Author

\section{Address for correspondence}

Dr. May Al-Maghrebi, PhD

Department of Biochemistry

Faculty of Medicine, Kuwait University

P.O. Box: 24923, Safat13110, Kuwait

Tel: 96524636447 Fax: 96525338908

E-mail address: malmaghrebi@hsc.edu.kw 
24 Running Title: Regulation of glycolytic enzymes in testicular ischemia reperfusion injury

\section{ABSTRACT}

Background: Testicular ischemia reperfusion injury (tIRI) is considered the mechanism underlying the pathology of testicular torsion and detorsion. Left untreated, tIRI can induce testis dysfunction, damage to spermatogenesis and possible infertility. In this study, we aimed to assess the activities and expression of glycolytic enzymes (GEs) in the testis and their possible modulation during tIRI. The effect of fructose 1,6-bisphosphate (FBP), a glycolytic intermediate, on tIRI was also investigated. Methods: Male Sprague-Dawley rats were divided into three groups: sham, unilateral tIRI, and tIRI + FBP ( $2 \mathrm{mg} / \mathrm{kg})$. tIRI was induced by occlusion of the testicular artery for $1 \mathrm{~h}$ followed by $4 \mathrm{~h}$ of reperfusion. FBP was injected peritoneally $30 \mathrm{~min}$ prior to reperfusion. Histological and biochemical analyses were used to assess damage to spermatogenesis, activities of major GEs, and energy and oxidative stress markers. The relative mRNA expression of GEs was evaluated by real-time PCR. ELISA and immunohistochemistry were used to evaluate the expression of p53 and TP53-induced glycolysis and apoptosis regulator (TIGAR). Results: Histological analysis revealed tIRI-induced spermatogenic damage as represented by a significant decrease in the Johnsen biopsy score. In addition, tIRI reduced the activities of hexokinase 1, phosphofructokinase-1, glyceraldehyde 3-phosphate dehydrogenase, and lactate dehydrogenase C. However, mRNA expression downregulation was detected only for hexokinase 1, phosphoglycerate kinase 2, and lactate dehydrogenase C. ATP and NADPH depletion was also induced by tIRI and was accompanied by an increased Malondialdehyde concentration, reduced glutathione level, and reduced superoxide dismutase and catalase enzyme 
46 activities. The immunoexpression of p53 and TIGAR was markedly increased after tIRI. The

47 above tIRI-induced alterations were attenuated by FBP treatment.

48 Discussion: Our findings indicate that tIRI-induced spermatogenic damage is associated with

49 dysregulation of GE activity and gene expression, which were associated with activation of the

50 TIGAR/p53 pathway. FBP treatment had a beneficial effect on alleviating the damaging effects

51 of tIRI. This study further emphasizes the importance of metabolic regulation for proper

52 spermatogenesis.

53

Keywords: Testicular ischemia reperfusion injury, Glycolytic enzymes, Fructose 1,6- 


\section{INTRODUCTION}

Testicular ischemia reperfusion injury (tIRI) represents the events that occur during testicular torsion and detorsion (TDD) (Filho et al., 2004). Prompt surgical intervention to counter rotation of the spermatic cord is necessary to relieve the acute ischemic episode. However, it has been established that tIRI induces the generation of reactive oxygen species (ROS) that trigger an array of signaling molecules, causing progressive damage to the structure and function of the testis (Filho et al., 2004; Antonuccio et al., 2006; Minutoli et al., 2012). A potentially negative outcome of tIRI is the increased risk of impaired spermatogenesis and reduced male fertility. Throughout spermatogenesis, germ cells have unique metabolic needs and utilize different metabolic pathways for energy production to ensure proper development (Boussouar \& Benahmed 2004; Rato et al., 2012). Therefore, the maintenance of metabolic requirements necessitates the cooperation of germ cells with Sertoli cells (SCs) to ensure proper spermatogenesis (Alves et al., 2014). Spermatogenesis is under hormonal control that involves SCs; thus, it can be inferred that the glycolytic metabolism of SCs might be affected by this hormonal signaling (Alves et al., 2013). Moreover, the metabolic status of the reproductive system is vital to maintain germ cell energy demands and survival. Several studies have reported on the implications of metabolic defects on male infertility in patients with Klinefelter syndrome, 
92 diabetes mellitus, or obesity (Alves et al., 2016a; Alves et al., 2015; Martins 2015; Rato et al., 93 2015).

94

sources. Spermatids predominantly use the TCA cycle for energy production, whereas spermatogonia depend on glycolysis for energy production (Robinson \& Fritz, 1981; Riera et al., 2002). SCs act as lactate producers in the testis by sustaining a high glycolytic flux, thus exhibiting Warburg-like metabolic behavior (Oliveira et al., 2015). This is very important for supporting the energetic needs of developing germ cells. Most of the glucose is converted to lactate, which is then converted to pyruvate by the enzyme lactate dehydrogenase C (LDHC). Interestingly, approximately $25 \%$ of the produced pyruvate becomes oxidized during the TCA cycle. This reaction is coupled with NADPH production, an indicator of the pentose phosphate pathway (PPP). Surplus glucose undergoes glycolysis to produce pyruvate that enters the mitochondria and becomes oxidized and decarboxylated by pyruvate dehydrogenase to form acetyl CoA that enters the TCA cycle. During this process, ATP is formed by ADP phosphorylation via the electron transport chain (Rato et al., 2002). Several glycolytic enzymes (GEs), including hexokinase isoenzyme 1 (HK1S), glucose-6-phosphate isomerase (GPI), phosphoglycerate kinase (PGK2), sperm-specific glyceraldehyde 3-phosphate (GAPDHS), and pyruvate kinase (PKS), have been identified and reported to play a key role in regulating glycolysis in germ cells(Gupta, 2013). An interesting glycolysis intermediate, fructose-1,6bisphosphate (FBP), has been shown to exert protective effects in several models of ischemia and hypoxia (Didlake et al., 1989; Farias et al., 1990; Karaca et al., 2002). It was also suggested that FBP can activate the PPP for anaerobic ATP production (Kelleher et al., 1995; Espanol et al., 1998). The PPP is involved in the regulation of cellular redox via NADPH supplementation. 
115 NADPH is considered a regulator of cellular redox potential by preserving cellular levels of 116 glutathione and catalase (Ben-Yosef, Boxer, \& Ross 1996; Salvemini et al., 1999). Similarly,

117 FBP was found to maintain cellular levels of glutathione and catalase in addition to upregulating 118 the activity of glucose-6-phosphate dehydrogenase, the rate-limiting enzyme of PPP. Therefore, 119 it is highly likely that FBP suppresses oxidative stress through PPP activation (Ahn et al., 2002). 120 In the present study, we evaluated the mRNA expression and activity of the major GEs required for energy production in the testis during tIRI. In parallel, testicular oxidative status and germ cell apoptosis were also assessed. Due to its reported protective and antioxidant effects, we investigated the effects of the exogenous administration of FBP on spermatogenesis, expression of GEs, and energy production in the testis. The effects of tIRI-induced ROS on the expression of p53 and its downstream transcriptional target TP53-induced glycolysis and apoptosis regulator (TIGAR) were also studied.

\section{MATERIALS AND METHODS}

\section{Ethics Statement}

The animal experimental protocol and procedures used in this study complied with the guidelines of the ethics committee on animal research at Kuwait University. The ethical use of animals at Kuwait University is in accordance with the guidelines of the International Council for Laboratory Animal Sciences (ICLAS). Male adult Sprague-Dawley rats (Charles River, Waltham, MA, USA) were acclimated to standard laboratory conditions of a 12-h light/12-h dark cycle at $25^{\circ} \mathrm{C}$, and were fed a standard diet and tap water ad libitum.

\section{Surgical Procedure}


138 The rats $(\mathrm{n}=18,200-250 \mathrm{~g}, 8$ weeks old $)$ were divided randomly into three groups of six rats

139 each. The three groups were: sham, tIRI, and tIRI + FBP. The surgical procedure has been

140 described previously (Al-Maghrebi, Renno \& Al-Ajmi, 2012). Briefly, all rats were anesthetized

141 with 50 mg/kg ketamine (Tekam, Hikma Pharmaceuticals, Amman, Jordan) and 2 mg/kg

142 xylazine (Rompun, Bayer GmbH, Leverkusen, Germany). The incision area was clean-shaven

143 and disinfected with betadine. Sham rats underwent a standard ilioinguinal incision at the left

144 side, and the left testis was exposed for $60 \mathrm{~min}$ before placing it again into the scrotal sac

145 followed by incision suturing. Sham animals were sacrificed after $4 \mathrm{~h}$. The rats subjected to tIRI

146 underwent a unilateral ischemic injury by occluding the left testicular artery with a non-traumatic

147 microvascular clamp (700 g of pressure) (Cat. No. RS-7440; Roboz Surgical Instruments Co.,

148 Gaithersburg, MD, USA) to cut off the blood supply to the testes for $1 \mathrm{~h}$. Thirty minutes prior to

149 testis reperfusion, the rats received an intraperitoneal injection (i.p.) injection of $300 \mu$ of saline

150 (vehicle). Blood flow was resumed after $1 \mathrm{~h}$ of ischemia by clamp removal, and testis

151 reperfusion was allowed for $4 \mathrm{~h}$ before animal sacrifice. A similar procedure was followed with

152 the third group that underwent tIRI + FBP, in which saline was substituted with a dose of $2 \mathrm{~g} / \mathrm{kg}$

153 FBP. FBP (Cat. No. F6803; Sigma-Aldrich, St. Louis, MO, USA) was administered as an i.p. of

$1542 \mathrm{mg} / \mathrm{kg} 30 \mathrm{~min}$ prior to reperfusion. The selected dose and method of delivery were based on

155 prior studies (Zhou J et al., 2014; Palanas et al., 1993). Zhou and colleagues, 2014, showed that

156 an i.p. FBP dose of 500 or $1,000 \mathrm{mg} / \mathrm{kg}$ provided neuroprotection in immature rats suffering

157 from repeated febrile convulsions. Palanas and colleagues, 1993, demonstrated that in contrast to

158 lower i.p. doses of FBP $(0.5$ or $1 \mathrm{~g} / \mathrm{kg})$ or the orally administered dose of $0.5 \mathrm{~g} / \mathrm{kg}$, an i.p.

159 injection of $2 \mathrm{~g} / \mathrm{kg} \mathrm{FBP}$ had the highest protective action (80\%) within $1 \mathrm{~h}$ of administration and

160 persisted for $5 \mathrm{~h}$ (Palanas et al., 1993). Furthermore, albino Swiss mice showed no toxicity 
161 symptoms after an i.p. administration of $800 \mathrm{mg} / \mathrm{kg}$ FBP. The availability of FBP for $5 \mathrm{~h}$ and low toxicity are important to evaluate its protective effects in our experimental design. For all three animal groups, the right contralateral testes were used as a positive internal control.

\section{Histological Examination}

The harvested testes were immediately immersed in Bouin's fixative for $24 \mathrm{~h}$, washed with PBS, and embedded in paraffin. Hematoxylin and eosin (H\&E) staining was used to stain 4- $\mu \mathrm{m}$ tissue sections. Spermatogenesis was evaluated by measuring the tissue biopsy score (TBS) using the Johnson scoring system, which is based on rating germ cell maturation in each seminiferous tubule using a score of 1-10 (Johnsen, 1970). In a blinded manner, 4 slides from each testis (6 contralateral and 6 ipsilateral testes) were used for scoring.

2

\section{Detection of Apoptosis}

Dewaxed and rehydrated 4- $\mu \mathrm{m}$ tissue sections were treated with proteinase $\mathrm{K}$ followed by incubation with the TUNEL reaction mixture at $37^{\circ} \mathrm{C}$ and then were mounted with DAPI.

Staining of non-apoptotic free DNA 3' ends was eliminated by adjusting the manufacturer's protocol (Cat. No. 11684795910; Roche-Diagnostics, Mannheim, Germany). TUNEL-stained nuclei were analyzed using the LSM 700 confocal laser scanning microscope (Carl Zeiss MicroImaging, München, Germany). TUNEL-stained nuclei were scored using 100 random seminiferous tubules from 2 slides/testis/rat. Images were acquired at $400 \times$ and $100 \times$ magnification for counting and presentation purposes, respectively. The investigator was blinded to the experimental group identity during the scoring process, and the data are presented as the mean $\pm \mathrm{SD}$. 


\section{Immunohistochemistry}

186

Each testis paraffin block was cut into 4-mm sections on silane-coated slides. The avidin-biotin complex method was used for p53 and TIGAR immunohistochemical staining. Tissues were rehydrated in a graded alcohol series followed by microwave retrieval using citrate buffer $(0.01$ $\mathrm{M}, \mathrm{pH}$ 6). The tissues were then treated for $30 \mathrm{~min}$ in $3 \% \mathrm{H}_{2} \mathrm{O}_{2}$, washed in PBS and blocked in blocking solution (Cat. No. 85-8943; Invitrogen, Frederick, MD, USA). The processed slides were incubated overnight with primary antibodies (1:100 dilution) for p53 (Cat. No. (DO-1) sc126; Santa Cruz Biotechnology, Santa Cruz, CA, USA) and for TIGAR (Cat. No. (Y-20) sc68239; Santa Cruz Biotechnology, Santa Cruz, CA, USA). The slides were then washed and treated with a Histostain-Plus IHC Kit, HRP, and broad-spectrum secondary antibody (60:40) (Cat. No. 85-8943; Thermo Fisher Scientific, Waltham, MA, USA) for 30 min at room temperature. The slides were then washed three times in PBS and treated with HRP-Streptavidin (Cat. No. N200; Thermo Fisher Scientific, Waltham, MA, USA) for 30 min at room temperature. Color development was then carried out using the Impact DAB kit (Cat. No. SK-4105; Vector Labs, Burlingame, CA, USA) for $30 \mathrm{sec}$ or until the desired brown color was obtained as seen under the microscope. The slides were then washed in distilled water and counterstained with hematoxylin for $5 \mathrm{~min}$, followed by bluing under tap water for $5 \mathrm{~min}$. The slides were dehydrated through a graded series of alcohol from $50 \%$ to absolute alcohol and then were cleared in xylene. Finally, a coverslip was mounted on top of the tissue sections using histology DPX mountant. The mean immunolabeling concentration was assessed by measuring the color intensity (Sum (Area) (pixel ${ }^{2}$ ) using Cell Sens Dimension Software (Olympus DP 71 camera) in the three experimental groups. Slide analysis was performed in a blinded manner. 


\section{RT and Real-time PCR}

Total RNA was purified from frozen testicular tissue samples using TRIzol (Invitrogen, USA)

following the manufacturer's instructions. Total RNA was reverse transcribed into complementary DNA (cDNA) using a high-capacity cDNA reverse transcription kit (RT) (Thermo Fisher Scientific, Waltham, MA, USA). The reaction mixtures included $20 \mathrm{U}$ of reverse transcriptase, $10 \mu \mathrm{l}$ of first-strand buffer, random primers, $0.5 \mathrm{mM}$ dNTP mix and $10 \mathrm{mM}$ DDT. $\mathrm{RT}$ reactions were carried out at $55^{\circ} \mathrm{C}$ for $50 \mathrm{~min}$. The gene expression levels of the following GEs were quantitated using real-time PCR: hexokinase ( $h k 1$, Cat. No. Rn00562436_m1), glucose-6-phosphate isomerase (gpi, Cat. No. Rn01475756_m1), 6-phosphofructokinase 1 (pfk, custom made), glyceraldehyde 3-phosphate dehydrogenase Sperm (gapdhs, Cat. No. Rn01476455_m1), phosphoglycerate kinase 2 (pgk2, Cat. No. Rn01511987_s1), and lactate dehydrogenase C (ldhc, Cat. No. Rn00568562_m1). The mRNA levels for the p53 upregulated modulator of apoptosis (puma, Cat. No. Rn00597992_m1) and survivin (birc5, Cat. No. Rn00574012_m1) were also measured. Gene-specific Taqman assays were mixed with TaqMan ${ }^{\circledR}$ universal PCR master mix (Thermo Fisher Scientific, Waltham, MA, USA) in a 96well plate. The reaction conditions recommended by the manufacturer were used in compliance with the ABI Prism 7000 SD system (Thermo Fisher Scientific, Waltham, MA, USA). The relative mRNA expression was calculated using the $2^{-\Delta \Delta C T}$ method (Livak \& Schmittgen, 2001). A rat $\beta$-actin (actb, Cat. No. Rn00667869_m1)-specific Taqman assay was used as an endogenous control.

\section{Protein Purification}


230 Total protein crude extracts were prepared from harvested testicular tissue. The tissues were 231 homogenized in a lysis buffer $(20 \mathrm{mM}$ Tris, $150 \mathrm{mM} \mathrm{NaCl}, 10 \mathrm{mM} \mathrm{Na} 2 \mathrm{EDTA}, 10 \mathrm{mM}$ EGTA, $2321 \%$ Triton $\mathrm{X}-100,1 \mathrm{mM} \mathrm{Na} \mathrm{VO}_{4}, 25 \mathrm{mM} \mathrm{NaF}, 1 \mu \mathrm{g} / \mathrm{ml}$ leupeptin, and $1 \mathrm{mM}$ PMSF) using a 233 tissue homogenizer. The protein concentrations were measured using the Bradford assay (Bio-

234 235

236

238

239

240

241

242

243

244

245 Rad, Hercules, CA, USA) and bovine serum albumin as the standard.

\section{Biochemical Assays}

Colorimetric assays were purchased from Sigma-Aldrich (St. Louis, MO, USA) to measure the enzymatic activities of HK1 (Cat. No. MAK091), GPI (Cat. No. MAK103), PFK1 (Cat. No. MAK093), GAPDH (Cat. No. MAK277), PGK2 (Cat. No. P7634), and LDHC (Cat. No. MAK066) following the manufacturer's protocols. The protein expression of total p53 and p-p53 (ser 15) was measured using an ELISA kit (Cat. No. PEL-P53-S15-T-1; RayBiotech, Inc., Norcross, GA, USA) following the manufacturer's protocol. The levels of ATP (Cat. No. MAK190) and NADPH (Cat. No. MAK038) were measured using their respective colorimetric assays according to the manufacturer's recommendations (Sigma-Aldrich, St. Louis, MO, USA). The testicular levels of glutathione (GSH, Cat. No. CS0260), malondialdehyde (MDA, Cat. No. MAK085) and the antioxidant enzymes superoxide dismutase (SOD, Cat. No. 19160) and catalase (CAT, Cat. No. CAT100) were determined using their respective colorimetric assays (Sigma-Aldrich, St. Louis, MO, USA) following the manufacturer's protocol.

\section{Statistical Analysis}

Statistical analysis for the obtained data was performed using GraphPad Prism (v 6.0). All of the data are presented as the mean \pm standard deviation (SD). Grubb's test and/or ROUT test were 
253

254

255

256

257

258

259

260

261

262

263

264

265

266

267

268

269

270

271

272

273

274

275

276

used to eliminate any outliers from the normal data distribution. Multiple group comparisons were performed using one-way analysis of variance (ANOVA) followed by the Holm-Sidak multiple comparisons test for the comparison of mean values. Statistical significance was accepted as $p<0.05$.

\section{RESULTS}

\section{Testicular spermatogenesis}

Figure 1 shows H\&E testicular sections from the sham, tIRI, and FBP-treated groups. In contrast to the normal histological appearance of testicular tissue in the sham and FBP-treated groups, the ipsilateral testes in the tIRI group showed seminiferous tubular atrophy, disruption of germ cell layers, and spermatogenic arrest. Compared with sham, the mean TBS in the ipsilateral testes from the tIRI group was significantly lower $(9.33 \pm 1.03$ vs. $5.67 \pm 0.52, p<0.0001)$, which was normalized after FBP treatment $(7.67 \pm 0.52, v s .5 .67 \pm 0.52, p=0.0002)$. The contralateral testes revealed no significant differences in testis histology or TBS among the three experimental groups.

\section{mRNA expression of glycolytic enzymes}

The relative mRNA expression was obtained and calculated for all of the evaluated genes (Table 1). The mRNA expression for gpi and $p g k 2$ showed no significant changes among the three experimental groups. However, significant downregulation of the mRNA expression of $h k 1(0.76$ \pm 0.46 vs. $1.00 \pm 0.26, p<0.05)$, pfk $(0.66 \pm 0.39$ vs. $1.00 \pm 0.27, p<0.05)$, gapdhs $(0.73 \pm 0.39$ vs. $1.00 \pm 0.32, p<0.05)$, and $l d h c(0.76 \pm 0.46 v s .1 .00 \pm 0.26, p<0.05)$ was calculated in the 
tIRI group compared with sham levels and was restored to almost sham levels in the FBP-treated group. The contralateral testes revealed no significant differences in mRNA expression among the three experimental groups.

\section{Glycolytic enzyme activities}

The enzymatic activities of HK1 $(1.11 \pm 0.27 v s .2 .08 \pm 0.30, p=0.0034)$, PFK1 (0.78 $\pm 0.10 v s$. $1.33 \pm 0.24, p=0.0016)$, GAPDHS $(1.05 \pm 0.21 v s .1 .49 \pm 0.14, p=0.0016)$ and LDHC $(1.07 \pm$ 0.17 vs. $2.02 \pm 0.41, p<0.0001)$ were significantly decreased as a result of tIRI compared with sham levels (Table 2). These activities were significantly increased in the FBP-treated group compared with that in the tIRI group (HK1: $1.87 \pm 0.38, p=0.0260 ;$ PFK1: $1.30 \pm 0.17, p=$ 0.0029; GAPDHS: $1.46 \pm 0.28, p=0.0040$; LDHC: $1.78 \pm 0.19, p=0.0017)$. Although there were notable decreases in the activities of GPI and PGK2 in the tIRI group, the decreases were not significantly different from those of the sham or FBP-treated group. The contralateral testes revealed no significant difference in enzymatic activities among the three experimental groups.

\section{Testicular levels of ATP and NADPH}

The levels of ATP and NADPH were evaluated in the three experimental groups (Figure 2). In the tIRI group, testicular tissue showed significantly reduced ATP levels $(0.41 \pm 0.08$ vs. $0.59 \pm$ $0.05, p=0.0087)$ and NADPH levels $(1.75 \pm 0.36 v s .2 .88 \pm 0.30, p=0.0004)$ compared with those in the sham group. FBP-treated rats exhibited sham-like levels of ATP $(0.57 \pm 0.12 v s$. $0.41 \pm 0.08, p=0.0286)$ and NADPH $(2.53 \pm 0.32$ vs. $1.75 \pm 0.36, p=0.0168)$ compared with tIRI. The contralateral testes revealed no significant differences in the evaluated parameters among the three experimental groups. 


\section{Testicular oxidative stress}

In the tIRI group, significantly low GSH $(0.33 \pm 0.03$ vs. $0.25 \pm 0.04, p=0.0002)$ and high MDA levels $(1.68 \pm 0.35$ vs. $1.05 \pm 0.20, p<0.0001)$ were accompanied by decreased activities of CAT $(82.55 \pm 8.52 v s .95 .32 \pm 3.91, p=0.0002)$ and $\operatorname{SOD}(81.23 \pm 0.95 v s .95 .67 \pm 3.59, p<$ 0.0001) compared with sham (Table 3). FBP treatment reduced testicular oxidative stress as indicated by normalized levels of GSH $(0.24 \pm 0.03, p=0.0002)$, MDA $(1.04 \pm 0.25, p<$ $0.0001)$, and CAT $(94.75 \pm 4.10, p=0.0003)$ and $\operatorname{SOD}(92.62 \pm 1.87, p=0.0004)$ activities. The contralateral testes showed no significant changes in these parameters.

\section{Germ cell apoptosis and p53/TIGAR signaling}

As shown in Figure 3, ROS-induced DNA damage is clearly visible in the ipsilateral testes subjected to tIRI compared with the sham group $(38.67 \pm 8.98 v s .0 .83 \pm 0.75, p<0.0001)$; this damage was prevented by FBP treatment $(9.83 \pm 4.62$ vs. $38.67 \pm 8.98, p<0.0001)$. As shown in Figure 4, DNA damage was accompanied by increased p53 phosphorylation (ser 15) (1.47 \pm 0.25 vs. $0.90 \pm 0.11, p<0.0001)$, upregulated PUMA mRNA expression $\mathrm{f}(1.71 \pm 0.28 v s .1 .00 \pm$ $0.06, p<0.05)$, and downregulated survivin mRNA expression $(0.66 \pm 0.15 v s .1 .00 \pm 0.16, p<$ 0.05) in the tIRI group compared with the sham group. Phosphorylation of p53 and the mRNA expression of PUMA and survivin reverted to sham levels in the FBP-treated group [0.96 \pm 0.21 $(p<0.0001), 1.10 \pm 0.15(p<0.05)$, and $1.14 \pm 0.14(p<0.05)$, respectively]. This result was also associated with significant increases in the immunostaining of both p53 and TIGAR in tIRIsubjected testes compared with the sham group [p53: 44,511 $\pm 14,731$ vs. 1,053 $\pm 337, p<$ 0.0001; TIGAR: 223,212 $\pm 61,975$ vs. 42,743 $\pm 22,900, p<0.0001]$ (Figure 5). FBP treatment 
323 significantly reduced the immunostaining of both proteins [p53: 5,757 $\pm 3,223$ vs. 44,511 \pm

324 14,731, $p<0.0001$; TIGAR: 95,124 $\pm 48,736$ vs. 223,212 $\pm 61,975, p<0.0001]$.

325

326

327

328

329

330

331

332

333

334

335

336

337

338

339

340

341

342

343

344

345

\section{DISCUSSION}

Testicular IRI is characterized by reduced spermatogenesis, which could affect testicular function in supporting male fertility. The regulation of carbohydrate metabolism and energy production is important in testicular cells to maintain proper spermatogenesis (Rato et al., 2012). Such processes are carried out through unique metabolic cooperation between somatic SCs and developing germ cells (Alves et al., 2014). Here, we tested the hypothesis that tIRI would affect the metabolic profile of the testis.

Glycolysis can be divided into two distinct stages: an energy-consuming stage to produce FBP from glucose, and a second stage comprising energy production via the degradation of FBP to pyruvate (Berg, Tymoczko, \& Stryer, 2002). Although SCs and germ cells express all of the enzymes of the glycolytic pathway, germ cells predominantly use the lactate produced by SCs for energy production (Oliveira et al., 2015; Boussouar and Benahmed, 2004). Our data indicate that the transcriptional deregulation of key regulatory GEs from the two glycolytic stages was coupled with respective reduced enzymatic activities, and both were associated with impaired spermatogenesis, increased oxidative stress and germ cell apoptosis. For germ cells, glycolysis is the major source of ATP required for sperm motility, capacitation, and fertilization (Miki, 2007; Mukai and Okuno, 2004; Travis et al., 2004; Williams and Ford, 2001). This result was supported by the localization of the major glycolytic enzymes HK1S, PFK, GAPDHS and LDHC as a unique cluster in the fibrous sheath of the flagellum and in close proximity to the dynein ATPase activity that generates the flagellar beat (Krisfalusi et al., 2006; Nakamura, Mori and 
346 Eddy, 2010; Tanii et al., 2007). The importance of their role in supporting sperm bioenergetics

347 and function was further realized in knockout mice for GAPDHS-/- (Miki et al., 2004) and PGK2-

348 /- (Danshina et al., 2010), which showed severely impaired fertility with glycolysis inhibition.

349 Although spermatogenesis appeared normal in $\mathrm{LDHC}^{-/-}$mice (Odet et al., 2013), the sperm

350 fertilization capacity was greatly compromised due to the inability to metabolize lactate for

351 energy production. In addition, immotile sperms had reduced PFK activity compared with motile

352 sperms (Kamp et al., 2007). Furthermore, metal-treated human ejaculates were found to exhibit

353 dose- and time-dependent effects on sperm motility due to the inhibition of GEs such as glucose-

354 6-phosphatase, fructose 1,6-diphosphatase, glucose-6-phosphate isomerase, and lactic

355

356

357

358

359

360

361

362

363

364

365

366

367

dehydrogenase (Kanwar et al., 1988). It was also suggested that the depletion of lactate levels in the testicular tissues of patients with Klinefelter syndrome, a common genetic cause of human infertility, was due to underlying alterations in the testicular metabolism supported by SCs (Alves et al., 2016a). Similarly, compromised levels of testicular lactate content were observed in type I diabetic men and were attributed to alterations in glycolysis-related transporters and enzymes and structural SC deformities, which might be related to impotency problems (Alves et al., 2015). Obesity is another metabolic disease that provides an immediate link between male infertility and deregulated metabolism (Alves et al., 2016b; Katib, 2015; Rato et al., 2014). Impaired sperm quality was associated with defects in energy metabolic pathways in rats fed a high-fat diet (Ferramosca et al., 2016; Rato et al., 2013). Collectively, these data strongly suggest that the impairment of testicular glycolysis due to the deregulated expression and activity of GEs in testicular somatic or germ cells would compromise testicular function and could increase the risk of male infertility. 
Regular and continuous oxygen supply to the testis is vital for its overall function and, most importantly, to promote proper spermatogenesis. Oxidative stress and a lowered antioxidant capacity are hallmarks of tIRI and are the bases of its pathophysiological consequences, among other factors (Turner and Lysiak, 2008; Al-Maghrebi, Kehinde and Anim, 2010). In our study, the decline in glycolytic flux during tIRI was accompanied by increased testicular oxidative stress as indicated by the low levels of NADPH, GSH, CAT and SOD. Under physiological conditions, it is thought that proliferating cells using aerobic glycolysis are naturally protected against OS due to the production of NADPH and GSH, which are natural antioxidant side products of the PPP (Kuehne et al., 2015). Thus, increased ROS production as a result of tIRI would disrupt the function of the enzymes and components of the metabolic and energy producing pathways in germ cells. A strong association was reported between increased ROS generation, abnormal semen parameters and male infertility (Ko, Sabangeh and Agarwal, 2014).

Recently, it was also reported that increased ROS levels in the serum and seminal fluid of infertile men negatively affected sperm mitochondrial respiration through the uncoupling of electron transport and ATP production (Ferramosca et al., 2013). Although considered non proliferative, SCs are characterized by a high glycolytic flux and are known as lactate producers due to their unique "Warburg-like metabolism" to support the continuous progression of spermatogenesis (Oliveira et al., 2015). This property indirectly renders SCs insensitive to physiological oxidative stress but not that induced by continuous external stimuli. Therefore, ROS can be considered a regulator of glycolytic flux in proliferative germ cells and nonproliferative SCs.

Oxygen supply insufficiency induced by ischemia or hypoxia also alters mitochondrial respiratory chain function, inhibits mitochondrial ATP synthase and subsequently reduces 
oxidative phosphorylation (Eales, Hollinshead, \& Tennant, 2016). Here, we demonstrated that testicular ATP levels are compromised in tIRI-subjected rats and were preserved after FBP treatment. Tissue reperfusion and the restoration of oxygen supply generate ROS, open mitochondrial pores and disrupt the proton balance, exacerbating ischemic injury and leading to ATP depletion (Baines, 2010; Halestrap, 2010). The beneficial effects of FBP in maintaining the intracellular ATP pool can occur at different levels. FBP is known to activate membrane $\mathrm{Na}^{+} / \mathrm{K}^{+}$ ATPase by increasing intracellular $\mathrm{Na}^{+}$and sustaining ionic equilibrium (Roig, Bartrons \& Bermudez, 1997), to stimulate PFK activity (Farias et al., 1986) and to act as an energy source by stimulating anaerobic ATP production (Bickler \& Buck, 1996). In the hypothermic heart, FBP protection was related to the increased production of intracellular glycolytic energy (Hua et al., 2003). Physiologically, each FBP molecule can produce four ATP molecules instead of two ATPs produced by glucose under aerobic conditions by bypassing the first two ATP-consuming reactions. Therefore, it can be hypothesized that during tIRI, the availability of FBP prior to the onset of reperfusion could have rescued the cell from the decline in the HK and PFK activities that require ATP and acted as a glycolytic substrate for the next ATP-generating glycolytic reactions.

The role of p53 in regulating spermatogenesis is commonly accepted (Almon et al., 1993) because its knockout in mice leads to more undifferentiated spermatogonia compared with wildtype mice (Beumer et al., 1998). However, little is known about the p53 regulation of glycolytic flux in testicular cells. Here, we show that tIRI-induced p53 overexpression was associated with increased TIGAR expression, p53 phosphorylation, upregulation of PUMA (apoptosis inducer), and downregulation of survivin (inhibitor of apoptosis), all of which were abolished by FBP treatment. The fate of the cell is determined by p53 in two directions: survival and death 
414 (Montero et al., 2013). Physiological levels of ROS trigger protective pathways, whereas p53

415 acts as a death signal under cytotoxic oxidative stress. It was reported that most p53-induced

416 apoptosis events are dependent on PUMA, a proapoptotic BCL-2 family protein (Jeffers et al.,

417 2003). The role of $\mathrm{p} 53$ in regulating carbohydrate metabolism was suggested by inducing its

418 downstream gene, TIGAR (Green and Chipuk, 2006). Under oxidative stress, p53-induced

419 TIGAR expression modulates the glycolytic pathway by lowering the levels of fructose 2,6-

420 bisphosphate, inhibiting glycolysis, and activating the PPP to protect against ROS-induced death

421 (Bensaad et al., 2006). However, under severe IRI, continued TIGAR expression could lead to

422 glycolysis shutdown and inhibition of ATP production with or without PPP activation (Bensaad,

423 Cheung and Vousden, 2009). A TIGAR-null mutation in mice was found to aggravate brain

424 ischemic injury and was associated with low NADPH and GSH levels (Li et al., 2014). In the

425 heart, p53 and TIGAR were also found to enhance hypoxia-induced inhibition of glycolysis and

426 myocyte apoptosis (Kimata et al., 2010). In mild renal IRI, p53-induced TIGAR expression

427 resulted in the inhibition of PFK1 and increased G6PD and NADPH levels, indicating the

428 redirection of the glycolytic pathway to the PPP (Kim, Devalaraja-Narashimha, \& Padanilam,

429 2015). However, under severe renal IRI, sustained TIGAR expression did not activate the PPP,

430 and p53 overexpression led to cell apoptosis (Kim, Devalaraja-Narashimha, \& Padanilam, 2015).

431 The results from this study suggest that tIRI-induced oxidative stress is toxic to the testicular

432 microenvironment, prompting apoptotic pathway activation through p53 overexpression and

433 phosphorylation and preventing additional global tissue damage. The inhibition of glycolysis

434 without activation of the PPP suggests that during tIRI, sustained TIGAR overexpression might

435 redirect glucose metabolism from energy production to nucleotide synthesis for DNA repair. 


\section{Conclusion}

438 In conclusion, alterations in the mRNA expression and activities of the major GEs appear to

439 contribute to the tIRI-induced damage to spermatogenesis and hamper cellular energetics. The

440 effects of FBP treatment were very beneficial in sustaining the ATP and antioxidant levels that

441 were depleted by tIRI-induced excessive ROS production and glycolysis shutdown. In addition,

442 the activation of p53 and its transcriptional target TIGAR during tIRI was clearly associated with

443 germ cell apoptosis and did not promote their survival. These findings show promise for FBP

444 application as an adjuvant treatment in the setting of TTD.

445

446

447

448

449

450

451

452

453

454

455

456

457

458

459 


\section{REFERENCES}

467

468

Ahn SM, Yoon HY, Lee BG, Park KC, Chung JH, Moon CH, Lee SH. 2002. Fructose-1,6diphosphate attenuates prostaglandin E2 production and cyclo-oxygenase-2 expression in UVB-irradiated HaCaT keratinocytes. British Journal of Pharmacology 137:497-503.

Al-Maghrebi M, Kehinde EO, Anim JT. 2010. Long term testicular ischemia-reperfusion injury-induced apoptosis: involvement of survivin down-regulation. Biochemical Biophysical Research Communications 395:342-347.

Al-Maghrebi M, Renno WM, Al-Ajmi N. 2012. Epigallocatechin-3-gallate inhibits apoptosis and protects testicular seminiferous tubules from ischemia/reperfusion-induced inflammation. Biochemical Biophysical Research Communications 420: 434-439.

Almon E, Goldfinger N, Kapon A, Schwartz D, Levine AJ, Rotter V. 1993. Testicular tissuespecific expression of the p53 suppressor gene. Developmental Biology 156:107-116.

Alves MG, Dias TR, Silva BM, Oliveira PF. 2014. Metabolic cooperation in testis as a pharmacological target: from disease to contraception. Current Molecular Pharmacology 7:83-95. 
Alves MG, Jesus TT, Sousa M, Goldberg E, Silva BM, Oliveira PF. 2016b. Male fertility and obesity: are ghrelin, leptin and glucagon-like peptide-1 pharmacologically relevant? Current Pharmaceutical Design 22:783-791.

Alves MG, Martins AD, Jarak I, Barros A, Silva J, Sousa M, Oliveira PF. 2016a. Testicular lactate content is compromised in men with Klinefelter Syndrome. Molecular Reproduction and Development 83:208-216.

Alves MG, Martins AD, Moreira PI, Carvalho RA, Sousa M, Barros A, Silva J, Pinto S, Simões T, Oliveira PF. 2015. Metabolic fingerprints in testicular biopsies from type 1 diabetic patients. Cell and Tissue Research 362:431-440.

Alves MG, Rato L, Carvalho RA, Moreira PI, Socorro S, Oliveira PF. 2013. Hormonal control of Sertoli cell metabolism regulates spermatogenesis. Cellular and Molecular Life Sciences 70:777-793.

Antonuccio P, Minutoli L, Romeo C, Nicòtina PA, Bitto A, Arena S, Altavilla D, Zuccarello B, Polito F, Squadrito F. 2006. Lipid peroxidation activates mitogen-activated protein kinases in testicular ischemia-reperfusion injury. Journal of Urology 176:1666-1672.

Baines CP. 2010. The cardiac mitochondrion: nexus of stress. Annual Reviews of Physiology 72:61-80.

Bensaad K, Cheung EC and Vousden KH. 2009. Modulation of intracellular ROS levels by TIGAR controls autophagy. EMBO Journal 28:3015-3026.

Bensaad K, Tsuruta A, Selak MA, Vidal MN, Nakano K, Bartrons R, Gottlieb E, Vousden KH. 2006. TIGAR, a p53-inducible regulator of glycolysis and apoptosis. Cell 126: 107120. 
Ben-Yosef O, Boxer P, Ross B. 1996. Assessment of the role of the glutathione and pentose phosphate pathways in the protection of primary cerebrocortical cultures from oxidative stress. Journal of Neurochemistry 66:2329-2337.

Berg JM, Tymoczko JL, Stryer L. 2002. Biochemistry. New York: W H Freeman. Available at http://www.ncbi.nlm.nih.gov/books/NBK22395/

Beumer TL, Roepers-Gajadien HL, Gademan IS, van Buul PP, Gil-Gomez G, Rutgers DH, de Rooij DG. 1998. The role of the tumor suppressor p53 in spermatogenesis. Cell Death and Differentiation 5:669-677.

Bickler PE, Buck LT. 1996. Effects of fructose-1,6-bisphosphate on glutamate release and ATP loss from rat brain slices during hypoxia. Journal of Neurochemistry 67:1463-1468.

Boussouar F, Benahmed M. 2004. Lactate and energy metabolism in male germ cells. Trends in Endocrinol and Metabolism 15:345-350.

Danshina PV, Geyer CB, Dai Q, Goulding EH, Willis WD, Kitto GB, McCarrey JR, Eddy EM, O'Brien DA. 2010. Phosphoglycerate kinase 2 (PGK2) is essential for sperm function and male fertility in mice. Biology of Reproduction 82:136-145.

Didlake R, Kirchner KA, Lewin J, Bower JD, Markov AK. 1989. Attenuation of ischemic renal injury with fructose 1,6-diphosphate. The journal of surgical research 47:220-226.

Eales KL, Hollinshead KE, Tennant DA. 2016. Hypoxia and metabolic adaptation of cancer cells. Oncogenesis 5:e1901-e1908.

Espanol MT, Litt L, Hasegawa K, Chang LH, Macdonald JM, Gregory G, James TL, Chan PH. 1999. Fructose-1,6-bisphosphate preserves adenosine triphosphate but not intracellular pH during hypoxia in respiring neonatal rat brain slices. Anesthesiology 88:461-472. 
525 Farias LA, Smith EE, Markov AK. 1990. Prevention of ischemichypoxic brain injury and 526 death in rabbits with fructose-1,6-diphosphate. Stroke 21:606-613.

527 Farias LA, Willis M, Gregory GA. 1986. Effects of fructose 1,6-diphosphate, glucose, and saline on cardiac resuscitation. Anesthesiology 65:595-601.

Ferramosca A, Conte A, Moscatelli N, Zara V. 2016. A high fat diet negatively affects rat sperm mitochondrial respiration. Andrology. In press.

Ferramosca A, Pinto Provenzano S, Montagna DD, Coppola L, Zara V. 2013. Oxidative stress negatively affects human sperm mitochondrial respiration. Urology 82:78-83.

Filho DW, Torres MA, Bordin AL, Crezcynski-Pasa TB, Boveris A. 2004. Spermatic cord torsion, reactive oxygen and nitrogen species and ischemia-reperfusion injury. Molecular Aspects of Medicine 25:199-210.

Goodson SG, Qiu Y, Sutton KA, Xie G, Jia W, O'Brien DA. 2012. Metabolic substrates exhibit differential effects on functional parameters of mouse sperm capacitation. Biology of Reproduction 87:7501-7515.

Gupta GS. 2013. Isoenzymes of glycolytic pathway in sperm: The unique sites for contraception. International Journal of Bioassays 2:1354-1374.

Halestrap AP. 2010. A pore way to die: the role of mitochondria in reperfusion injury and cardioprotection. Biochemical Society Transactions 38:841-860.

Hua D, Zhuang X, Ye J, Wilson D, Chiang B, Chien S. 2003. Using fructose-1,6-diphosphate during hypothermic rabbit-heart preservation: a high-energy phosphate study. Journal of Heart and Lung Transplantation 22:574-582.

Johnsen SG. 1970. Testicular biopsy score count - a method for registration of spermatogenesis in human testes: normal values and results of 335 hypogonadal males. Hormones 1: 2-25. 
Kamp G, Schmidt H, Stypa H, Feiden S, Mahling C, Wegener G. 2007. Regulatory properties of 6-phosphofructokinase and control of glycolysis in boar spermatozoa. Reproduction 133:29-40.

Kanwar U, Chadha S, Batla A, Sanyal SN, Sandhu R. 1988. Effect of selected metal ions on the motility and carbohydrate metabolism of ejaculated human spermatozoa. Indian Journal of Physiology and Pharmacology 32:195-201.

Karaca M, Kilic E, Yazici B, Demir S, de L. 2002. Ischemic stroke in elderly patients treated with a free radical scavenger-glycolytic intermediate solution: a preliminary pilot trial. Neurological research 24:73-80.

Katib A. 2015. Mechanisms linking obesity to male infertility. Central European Journal of Urology 68:79-85.

Kelleher JA, Chan PH, Chan TYY, Gregory GA. 1995. Energy metabolism in hypoxic astrocytes: protective mechanism of fructose-1,6-bisphosphate. Neurochemistry research 20:785-792.

Kim J, Devalaraja-Narashimha K, Padanilam BJ. 2015. TIGAR regulates glycolysis in ischemic kidney proximal tubules. American Journal of Physiology. Renal Physiology 308:F298-308.

Kimata M, Matoba S, Iwai-Kanai E, Nakamura H, Hoshino A, Nakaoka M, Katamura M, Okawa Y, Mita Y, Okigaki M, Ikeda K, Tatsumi T, Matsubara H. 2010. p53 and TIGAR regulate cardiac myocyte energy homeostasis under hypoxic stress. American Journal of_Physiology. Heart and Circulation Physiology 299:H1908-H1916.

Krisfalusi M, Miki K, Magyar PL, O'Brien DA. 2006. Multiple glycolytic enzymes are tightly bound to the fibrous sheath of mouse spermatozoa. Biology of Reproduction 75:270-278. 
Ko EY, Sabanegh ES, Jr., Agarwal A. 2014. Male infertility testing: Reactive oxygen species and antioxidant capacity. Fertility and Sterility 102:1518-1527.

Kuehne A, Emmert H, Soehle J, Winnefeld M, Fischer F, Wenck H, Gallinat S, Terstegen L, Lucius R, Hildebrand J, Zamboni N. 2015. Acute Activation of Oxidative Pentose Phosphate Pathway as First-Line Response to Oxidative Stress in Human Skin Cells. Molecular Cell 59:359-371.

Li M, Sun M, Cao L, Gu JH, Ge J, Chen J, Han R, Qin YY, Zhou ZP, Ding Y, Qin ZH. 2014. A TIGAR-regulated metabolic pathway is critical for protection of brain ischemia. Journal of Neuroscience 34:7458-7471.

Livak KJ, Schmittgen TD. 2001. Analysis of relative gene expression data using realtime quantitative PCR and the 2( Delta Delta C(T)) Method. Methods 25:402-408.

Martins AD, Moreira AC, Sá R, Monteiro MP, Sousa M, Carvalho RA, Silva BM, Oliveira PF, Alves MG. 2015. Leptin modulates human Sertoli cells acetate production and glycolytic profile: a novel mechanism of obesity-induced male infertility? Biochimica et Biophysica Acta 1852:1824-1832.

Miki, K. 2007. Energy metabolism and sperm function. Soc. Reproduction and Fertility Supplement 65:309-325.

Miki K, Qu W, Goulding EH, Willis WD, Bunch DO, Strader LF, Perreault SD, Eddy EM, O'Brien DA. 2004. Glyceraldehyde 3-phosphate dehydrogenase-S, a sperm-specific glycolytic enzyme, is required for sperm motility and male fertility. Proceedings of the National Academy of Science USA 101:16501-16506.

Minutoli L, Bitto A, Squadrito F, Irrera N, Rinaldi M, Nicotina PA, Arena S, Magno C, Marini H, Spaccapelo L, Ottani A, Giuliani D, Romeo C, Guarini S, Antonuccio P, 
Altavilla D. 2011. Melanocortin 4 receptor activation protects against testicular ischemiareperfusion injury by triggering the cholinergic antiinflammatory pathway. Endocrinology. 152:3852-3861.

Montero J, Dutta C, van Bodegom D, Weinstock D, Letai A. 2013. p53 regulates a nonapoptotic death induced by ROS. Cell Death and Differentiation 20:1465-1474.

Mukai C, Okuno M. 2004. Glycolysis plays a major role for adenosine triphosphate supplementation in mouse sperm flagellar movement. Biology of Reproduction 71:540-547.

Nakamura N, Mori C, Eddy EM. 2010. Molecular complex of three testis-specific isozymes associated with the mouse sperm fibrous sheath: hexokinase 1, phosphofructokinase $\mathrm{M}$, and glutathione S-transferase mu class 5. Biology of Reproduction 82:504-515.

Odet F, Gabel S, London RE, Goldberg E, Eddy EM. 2013. Glycolysis and mitochondrial respiration in mouse LDHC-null sperm. Biology of Reproduction 88:95,1-7.

Oliveira PF, Martins AD, Moreira AC, Cheng CY, Alves MG. 2015. The Warburg effect revisited-lesson from the Sertoli cell. Medicinal Research Reviews 35:126-151.

Planas ME, Sánchez S, González P, Rodrigues de Oliveira J, Bartrons R. 1993. Protective effect of fructose 1,6-bisphosphate against carrageenan-induced inflammation. European Journal of Pharmacology 237:251-255.

Rato L, Alves MG, Cavaco JE, Oliveira PF. 2014. High-energy diets: a threat for male fertility? Obesity Reviews 15:996-1007.

Rato L, Alves MG, Dias TR, Lopes G, Cavaco JE, Socorro S, Oliveira PF. 2013. Highenergy diets may induce a pre-diabetic state altering testicular glycolytic metabolic profile and male reproductive parameters. Andrology 1:495-504. 


\section{Rato L, Alves MG, Duarte AI, Santos MS, Moreira PI, Cavaco JE, Oliveira PF. 2015.} Testosterone deficiency induced by progressive stages of diabetes mellitus impairs glucose metabolism and favors glycogenesis in mature rat Sertoli cells. The International Journal of Biochemistry and Cell Biology 66:1-10.

Rato L, Alves MG, Socorro S, Duarte AI, Cavaco JE, Oliveira PF. 2012. Metabolic regulation is important for spermatogenesis. Nature Reviews Urology 9:330-338.

Riera MF, Meroni SB, Schteingart HF, Pellizzari EH, Cigorraga SB. 2002. Regulation of lactate production and glucose transport as well as of glucose transporter 1 and lactate dehydrogenase A mRNA levels by basic fibroblast growth factor in rat Sertoli cells. Journal of Endocrinology 173:335-343.

Robinson R, Fritz IB. 1981. Metabolism of glucose by Sertoli cells in culture. Biology of Reproduction 24:1032-1041.

Roig, T., Bartrons, R., Bermudez, J. 1997. Exogenous fructose-1,6-diphosphate reduces $\mathrm{K}^{+}$ permeability in isolated rat hepatocytes. American Journal of Physiology 273:C473-C478.

Salvemini F, Franzé A, Iervolino A, Filosa S, Salzano S, Ursini MV. 1999. Enhanced glutathione levels and oxidoresistance mediated by increased glucose-6-phosphate dehydrogenase expression. Journal of Biological Chemistry 274:2750-2757.

Tanii I, Yagura T, Inagaki N, Nakayama T, Imaizumi K, Yoshinaga K. 2007. Preferential localization of rat GAPDS on the ribs of fibrous sheath of sperm flagellum and its expression during flagellar formation. Acta Histochemica et Cytochemica 40:19-26.

Travis AJ, Tutuncu L, Jorgez CJ, Ord TS, Jones BH, Kopf GS, Williams CJ. 2004. Requirements for glucose beyond sperm capacitation during in vitro fertilization in the mouse. Biology of Reproduction 71:139-145. 
639 Turner TT, Lysiak JJ. 2008. Oxidative stress: a common factor in testicular dysfunction.

$640 \quad$ Journal of Andrology 29:488-498.

641 Williams AC, Ford WC. 2001. The role of glucose in supporting motility and capacitation in 642 human spermatozoa. Journal of Andrology 22:680-695.

643

644

645

646

647

648

649

650

651

652

653 654

655

647

649

50 651 652 653 655
Zhou J, Wang F, Zhang J, Gao H, Yang Y, Fu R. 2014. Repeated febrile convulsions impair hippocampal neurons and cause synaptic damage in immature rats: neuroprotective effect of fructose-1,6-diphosphate. Neural Regeneration Research 9:937-942.

\section{6}

648 


\section{1}

Figure 1 Histological analysis of testicular tissue.

$H \& E$ sections of rat ipsilateral testes showing low $(A, B$ and $C ; 10 x)$ and high $(D, E$ and $F$; $40 \times$ ) magnifications of the histological changes from the three experimental groups. ( $A$ and

D) Representative images of ipsilateral testes from the sham group showing a normal seminiferous tubule structure and normal germ cell layer arrangement. ( $B$ and $E$ ) Histological sections of ipsilateral testes from the tIRI group showing seminiferous tubule atrophy and disrupted germ cell layers. ( $C$ and F) Examples of histological findings of the FBP-treated group (2 mg/kg i.p.) showing preserved histological morphology of the seminiferous tubules. 


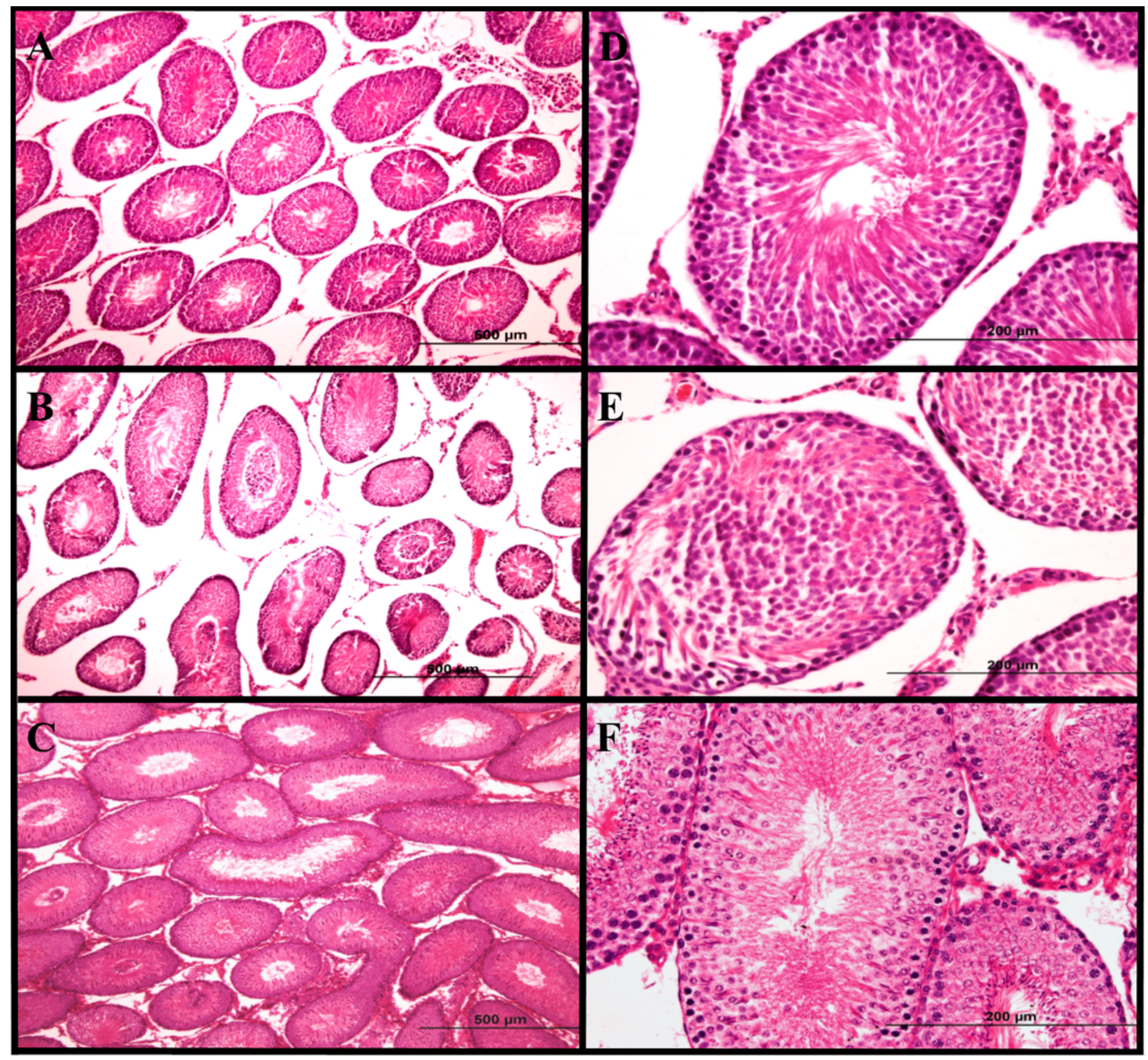


2

Figure 2 FBP effects on ATP and NADPH levels.

(A) tIRI-induced ATP depletion $\left({ }^{*} p=0.0087\right)$ was preserved in the FBP-treated group $\left({ }^{*} p=\right.$ 0.0286). (B) The tIRI-induced decrease in NADPH levels $\left({ }^{*} p=0.0004\right)$ was alleviated by FBP treatment ( $\left.{ }^{*} p=0.0168\right)$. Data analysis was performed using one-way analysis of variance (ANOVA) followed by the Holm-Sidak multiple comparisons test. Data are presented as the mean $\pm S D(n=6)$. The significance of the data is indicated with ${ }^{*}$ compared with the sham group and \# compared with the tIRI group.

A

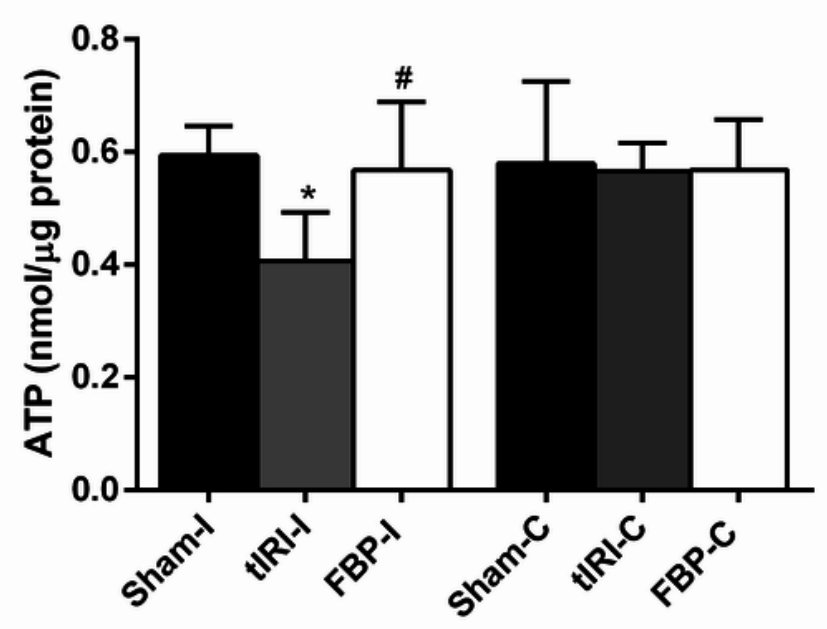

B

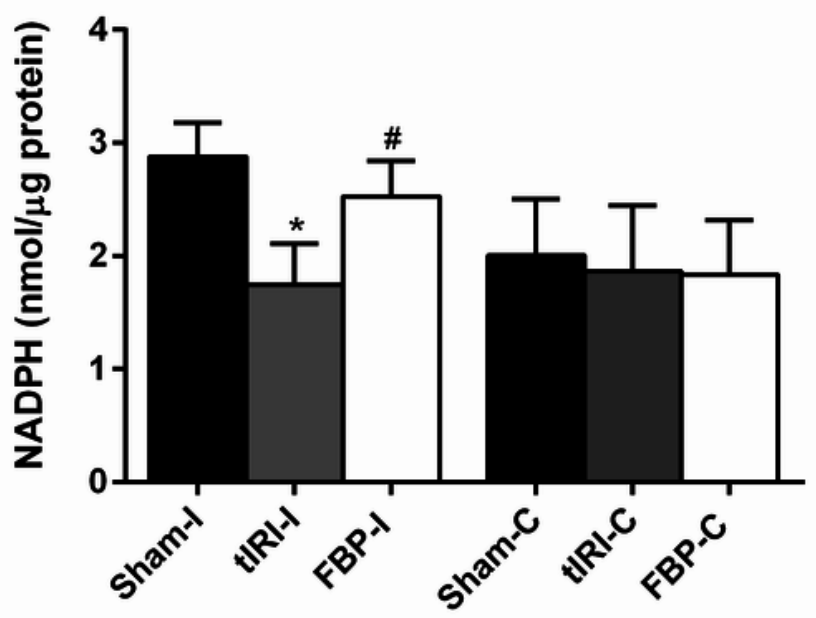




\section{3}

Figure 3 Germ cell apoptosis (GCA) assessed by TUNEL immunohistofluorescence.

( $A, D$, and $G)$ Representative images of GCA in sham rats. (B, E, and H) Increased number of TUNEL-positive nuclei in the tIRI group. (C, F, and I) FBP-treated group showing a diminished number of TUNEL-positive nuclei. Fluorescence staining used in the images: $A, D$, and $G=$ TUNEL; $B, E$, and $\mathrm{H}=\mathrm{DAPI}$, and $\mathrm{C}, \mathrm{F}$, and $\mathrm{I}=$ Merged.

*Note: Auto Gamma Correction was used for the image. This only affects the reviewing manuscript. See original source image if needed for review. 


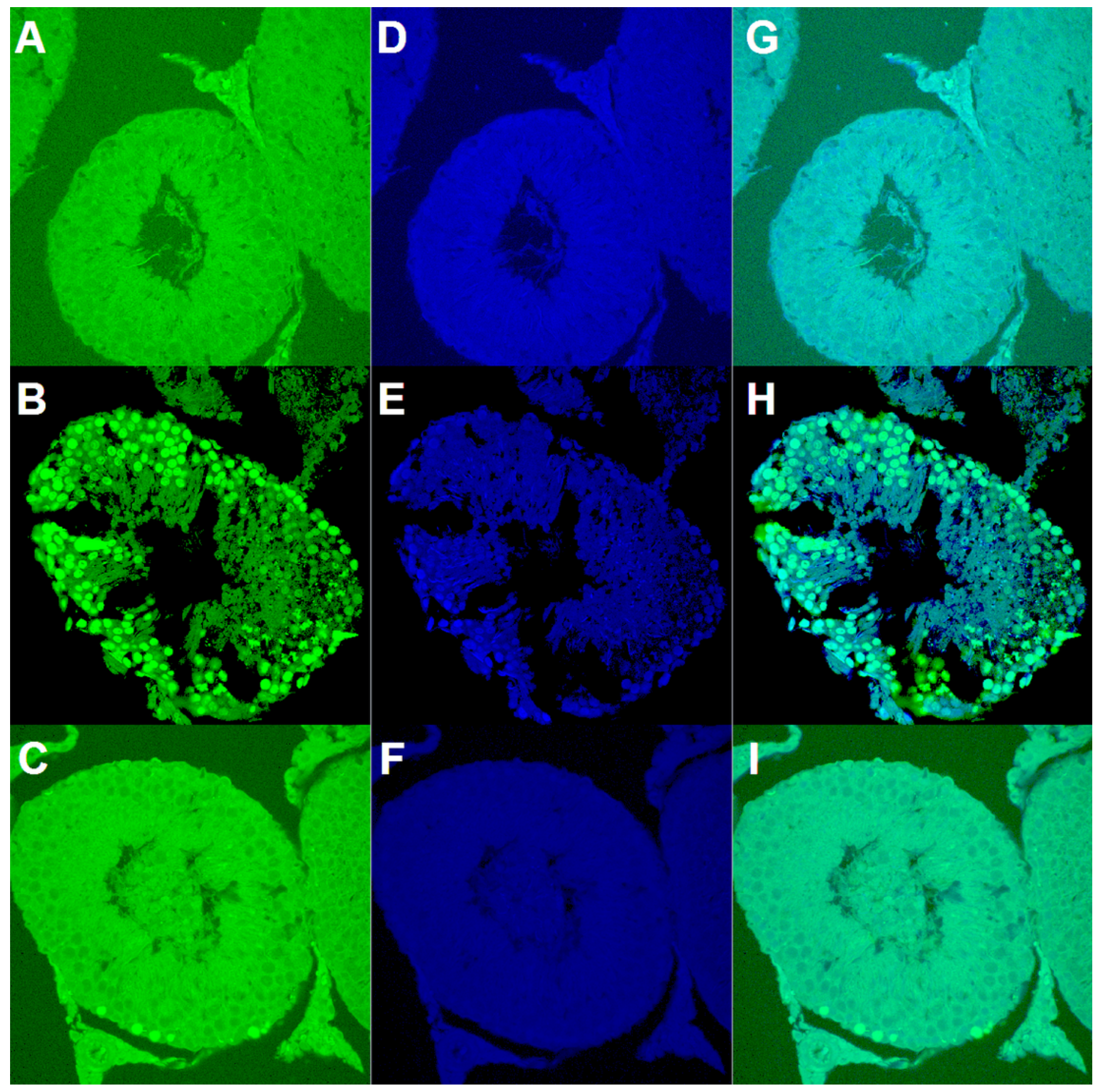




\section{4}

Figure 4 Phosphorylation of p53 and modulation of its downstream genes.

(A) Increased p53 phosphorylation (ser 15) was induced by tIRI ( $p<0.0001)$ and was inhibited by FBP treatment ( $\left.{ }^{\prime} p<0.0001\right)$. Real-time PCR was used to measure the relative mRNA expression of (B) PUMA and (C) survivin. PUMA mRNA levels were increased during tIRI $\left({ }^{*} p<0.05\right)$, whereas survivin mRNA was decreased $\left({ }^{*} p<0.05\right)$. FBP treatment normalized the relative mRNA expression of PUMA ( $\left.{ }^{*} p<0.05\right)$ and survivin $(* p<0.05)$. Data analysis was performed using one-way analysis of variance (ANOVA) followed by the Holm-Sidak multiple comparisons test. Data are presented as the mean $\pm S D(n=6)$. The significance of the data is indicated with ${ }^{*}$ compared with the sham group and ${ }^{*}$ compared with the tIRI group.

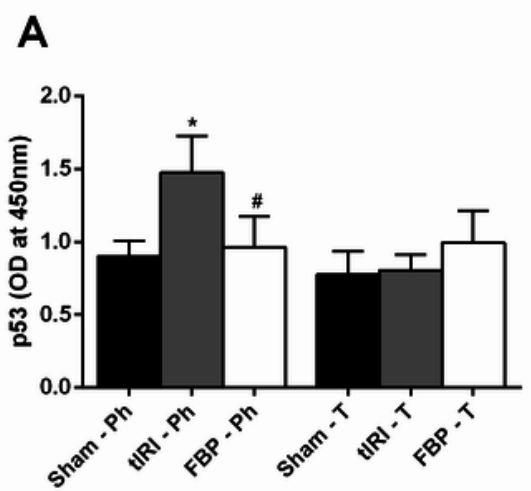

B

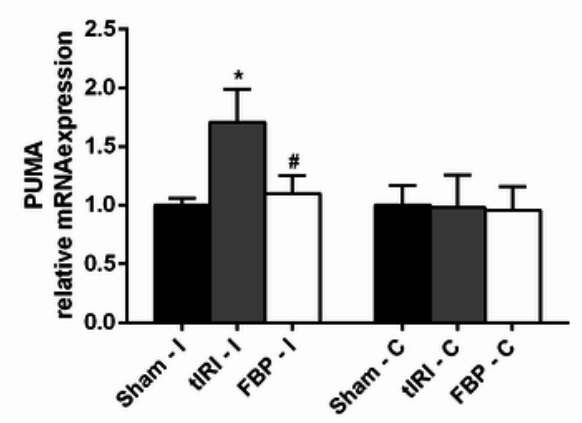

C

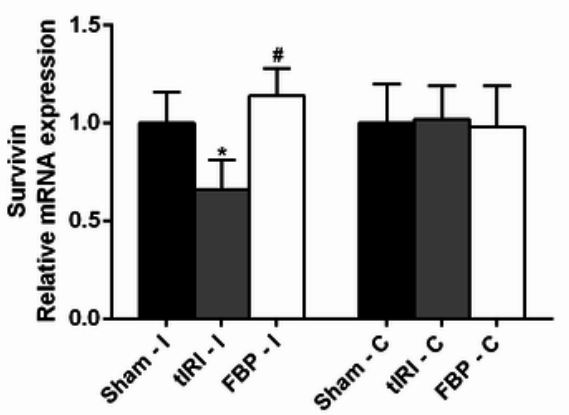




\section{5}

Figure 5 Immunoexpression of p53 and TIGAR in paraffin-embedded ipsilateral testicular tissue.

(A and D) The sham group showing very weak immunostaining of the p53 and TIGAR antibodies, respectively, in the seminiferous tubules layers of the rat testes. (B and $E$ ) Examples of p53 and TIGAR immunostaining showing a notable increase in their immunoexpression after tIRI. (C and F) FBP treatment of tIRI-subjected rats showed a decrease in the p53 and TIGAR immunolabeling intensity in the testes compared with the tIRI group. Magnification $=40 \mathrm{x}$. 


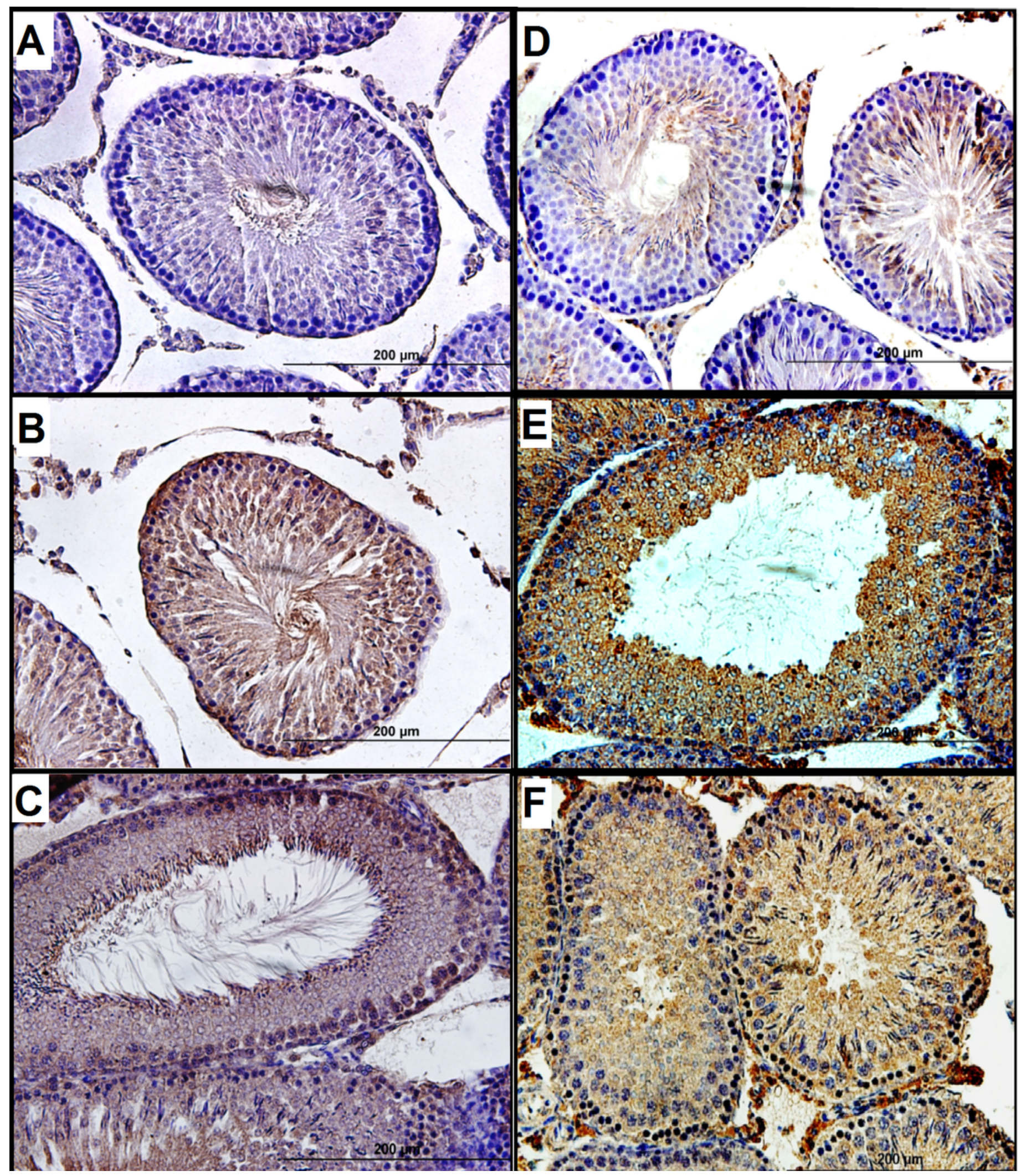




\section{Table 1 (on next page)}

Relative mRNA expression [RQ $\left(2^{-\Delta \Delta C T}\right)$ ] of glycolytic enzymes 


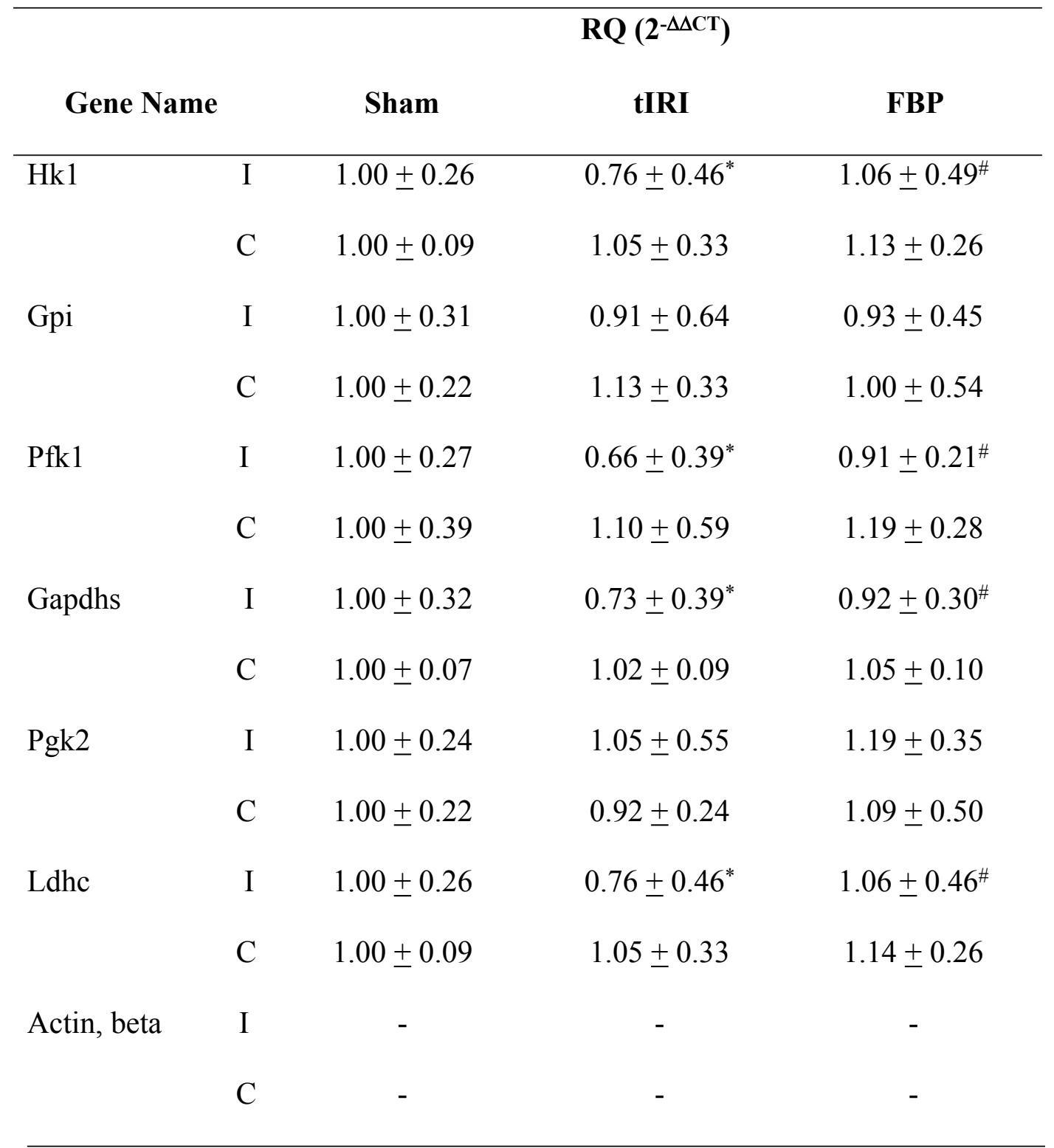

Notes.

${ }^{1}$ Rats received an i.p. injection of FBP $(2 \mathrm{mg} / \mathrm{kg}) 30 \mathrm{~min}$ prior to reperfusion.

Data analysis was determined by the one way analysis of variance (ANOVA) accompanied by the Holms-Sidak multiple comparisons test. Data are presented as mean $\pm \mathrm{SD}(\mathrm{n}=6)$. 
2

3

4

5

6

7

8

9

10

11

12

13

14

15

16

17

18

19

20

11

13

15

18

* tIRI compared to sham; " FBP compared to tIRI.

I ipsilateral; C contralateral.

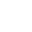

6

7

8

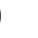




\section{Table 2 (on next page)}

Activities of glycolytic enzymes 


\begin{tabular}{|c|c|c|c|c|c|c|}
\hline & & Sham & tIRI & $p$ value ${ }^{*}$ & $\mathrm{FBP}^{1}$ & $p$ value $^{\#}$ \\
\hline \multirow[t]{2}{*}{ HK1 } & I & $2.08 \pm 0.30$ & $1.11 \pm 0.27$ & 0.0034 & $1.87 \pm 0.38$ & 0.0260 \\
\hline & $\mathrm{C}$ & $1.72 \pm 0.43$ & $1.71 \pm 0.48$ & ns & $1.55 \pm 0.70$ & ns \\
\hline \multirow[t]{2}{*}{ GPI } & $\mathrm{I}$ & $0.91 \pm 0.11$ & $0.77 \pm 0.12$ & 0.2046 & $0.71 \pm 0.16$ & 0.8686 \\
\hline & $\mathrm{C}$ & $0.73 \pm 0.14$ & $0.88 \pm 0.10$ & ns & $0.79 \pm 0.09$ & ns \\
\hline \multirow[t]{2}{*}{ PFK1 } & I & $1.33 \pm 0.24$ & $0.78 \pm 0.10$ & 0.016 & $1.30 \pm 0.17$ & 0.0029 \\
\hline & $\mathrm{C}$ & $1.2 \pm 0.21$ & $1.08 \pm 0.30$ & ns & $1.42 \pm 0.25$ & ns \\
\hline \multirow[t]{2}{*}{ GAPDHS } & I & $1.49 \pm 0.14$ & $1.05 \pm 0.21$ & 0.0016 & $1.46 \pm 0.28$ & 0.0040 \\
\hline & $\mathrm{C}$ & $1.36 \pm 0.15$ & $1.32 \pm 0.18$ & ns & $1.37 \pm 0.16$ & ns \\
\hline \multirow[t]{2}{*}{ PGK2 } & I & $0.98 \pm 0.21$ & $0.77 \pm 0.09$ & 0.1388 & $0.81 \pm 0.14$ & 0.9894 \\
\hline & $\mathrm{C}$ & $0.92 \pm 0.19$ & $0.84 \pm 0.15$ & ns & $0.83 \pm 0.17$ & ns \\
\hline \multirow[t]{2}{*}{ LDHC } & I & $2.02 \pm 0.41$ & $1.07 \pm 0.17$ & $<0.0001$ & $1.78 \pm 0.19$ & 0.0017 \\
\hline & $\mathrm{C}$ & $2.02 \pm 0.34$ & $2.02 \pm 0.16$ & $\mathrm{~ns}$ & $1.84 \pm 0.43$ & ns \\
\hline
\end{tabular}

\section{Notes.}

${ }^{1}$ Rats received an i.p. injection of FBP (2 mg/kg) $30 \mathrm{~min}$ prior to reperfusion.

Enzyme activities are expressed in milliunits/ $\mu \mathrm{g}$ protein and data are presented as mean $\pm \mathrm{SD}$ $(n=6)$.

Data analysis was determined by the one way analysis of variance (ANOVA) accompanied by the Holms-Sidak multiple comparisons test.

* tIRI compared to sham; " FBP compared to tIRI.

I ipsilateral; C contralateral. 


\section{Table 3 (on next page)}

Levels of oxidative stress markers 


\begin{tabular}{|c|c|c|c|c|c|c|}
\hline & & Sham & tIRI & $p$ value* & $\mathrm{FBP}^{1}$ & $p$ value ${ }^{\#}$ \\
\hline \multirow[t]{2}{*}{ GSH } & $\mathrm{I}$ & $0.25 \pm 0.04$ & $0.33 \pm 0.03$ & 0.0002 & $0.23 \pm 0.01$ & $<0.0001$ \\
\hline & $\mathrm{C}$ & $0.22 \pm 0.02$ & $0.21 \pm 0.02$ & ns & $0.19 \pm 0.01$ & ns \\
\hline \multirow[t]{2}{*}{ MDA } & I & $1.05 \pm 0.20$ & $1.68 \pm 0.35$ & $<0.0001$ & $1.04 \pm 0.25$ & $<0.0001$ \\
\hline & $\mathrm{C}$ & $1.03 \pm 0.07$ & $0.98 \pm 0.06$ & ns & $1.01 \pm 0.08$ & ns \\
\hline \multirow[t]{2}{*}{ SOD } & I & $95.67 \pm 3.59$ & $81.23 \pm 0.95$ & $<0.0001$ & $92.62 \pm 1.87$ & 0.0004 \\
\hline & $\mathrm{C}$ & $94.12 \pm 2.48$ & $92.03 \pm 3.52$ & ns & $90.53 \pm 7.23$ & ns \\
\hline \multirow[t]{2}{*}{ CAT } & $\mathrm{I}$ & $95.32 \pm 3.91$ & $82.55 \pm 8.52$ & 0.0002 & $94.75 \pm 4.10$ & 0.0003 \\
\hline & $\mathrm{C}$ & $94.07 \pm 4.17$ & $92.32 \pm 3.19$ & ns & $97.09 \pm 0.98$ & ns \\
\hline
\end{tabular}

Notes.

${ }^{1}$ Rats received an i.p. injection of FBP (2 mg/kg) $30 \mathrm{~min}$ prior to reperfusion.

Parameter units: GSH (nmol/ $\mu \mathrm{g})$; MDA $(\mu \mathrm{M})$; SOD (inhibition rate \%); and CAT (units/ml).

Data analysis was determined by the one way analysis of variance (ANOVA) accompanied by the Holms-Sidak multiple comparisons test. Data are presented as mean \pm SD $(n=6)$.

* tIRI compared to sham; " FBP compared to tIRI.

I ipsilateral; C contralateral. 